\title{
Ship Hull Principal Dimensions Optimization Employing Fuzzy Decision-Making Theory
}

\author{
Chen Jianping, ${ }^{1} \mathrm{Xu}$ Jie, ${ }^{2}$ Gong You, ${ }^{1}$ and $\mathrm{Xu} \mathrm{Li}^{3}$ \\ ${ }^{1}$ School of Ship Engineering, Guangzhou Maritime Institute, Guangzhou, China \\ ${ }^{2}$ School of Automation, Guangdong University of Technology, Guangzhou, China \\ ${ }^{3}$ Fujian Chuanzheng Communications College, Fuzhou, China \\ Correspondence should be addressed to Chen Jianping; wchchenjp@sina.com
}

Received 12 May 2016; Revised 31 October 2016; Accepted 16 November 2016

Academic Editor: Francisco Chicano

Copyright (C) 2016 Chen Jianping et al. This is an open access article distributed under the Creative Commons Attribution License, which permits unrestricted use, distribution, and reproduction in any medium, provided the original work is properly cited.

\begin{abstract}
The paper presents an optimization method for the ship hull principal dimensions scheme employing the fuzzy decision-making theory. First of all, the paper establishes the fuzzy decision-making model of the ship hull principal dimensions optimization, and then a series of ship hull principal dimensions schemes are accordingly constructed by employing the variable value method. On the basis of this, the fuzzy decision-making method is employed to evaluate the series ship hull principal dimensions schemes. Finally, the optimal ship hull principal dimensions scheme is obtained. The example demonstration verified the proposed method's validity for ship hull principal dimensions optimization economic performance.
\end{abstract}

\section{Introduction}

For the modern ship design, especially the civil transport ship design, it is important not only to satisfy the design specifications with good technical performance but also to consider ship's economic performance. In the process of designing and constructing a new ship, there are different technical design schemes, but their economic benefits are different too. The optimal technical scheme can be obtained through the economic evaluation for various ship form technical schemes. Conversely, if one-sided pursuit of "advanced" technical indicators in the design process ignores the ship's economic benefits, it would lead to the unreasonable design and cause missteps in economy by the operation of the ship. Similar to this kind of design mistakes it is not uncommon in practice.

The ship form optimization is always nonlinear problem. The optimization variables include the ship main dimensions, ship hull form coefficients, ship's speed, and main engine power. The ship form optimization problem is a complex nonlinear optimization problem. In fact, ship hull form optimization problem is a multiobjective decision-making one $[1,2]$. For multiobjective decision-making problems, there are many methods to evaluate their advantages and disadvantages, such as weight sum method, analytic hierarchy process, and ideal index planning [3-6]. There is comparability and conflict between different goals. Multiobjective optimization problem is not only a simple problem to determine the objective criteria, but it is how to choose an objective criteria for multiobjective decision-making problem [7-11]. It is the key to establishing a set of good decision criteria. Due to different objective function or weight selected, the optimization results are always different. The decision results are often relativity and subjectivity with a certain degree, not truly reflecting the objective facts.

In summary, the paper introduced the related decisionmaking methods of ship design to make the ship design decision-making to develop quantitative and scientific direction, and some methods show a good prospect in ship design decision-making. But it should be noted that the existing methods should be effectively applied to the ship form demonstration in practice, and it is not mature enough to solve real problems. In the aspects of research method and theory, it still needs to be further improved. The paper employed fuzzy decision-making theory to evaluate the ship form optimization which is a multiobjective 
decision-making problem. The optimal ship form design scheme can be obtained by sorting the economic evaluation indicators. This provides a new direction for solving the optimization problem of ship hull principal dimensions.

To the end, the paper verified the validity of the proposed method with an example demonstration of Pearl River main line 3000-ton bulk carrier.

\section{Ship Technical and Economic Indicators}

In the process of the new ship designing, firstly, it is usually important to develop a series of feasible ship form schemes based on the requirements and operating conditions and then carry out technical and economic evaluation for these schemes. Finally, the optimal scheme can be obtained from these schemes evaluated. The purpose of economic evaluation is to improve the design of the ship. It is not only a prelude to design a new ship but also an important part of the ship design, which involves a wide range, a large number of factors, and strong technical policy. In a sense, the ship technical and economic evaluation plays a decisive role in the quality and success of the design of the ship. The ship form optimization problem is a multiparameter, multiobjective decision-making problem, which is made up of a series of ship form design schemes. Ship design scheme is determined by the technical performance, economic performance, operation performance, and so on. In the paper, the fuzzy decision-making method is used to solve the ship form optimization problem with ship technical and economic performance.

\section{Fuzzy Comprehensive Evaluation Modeling}

For the same ship design requirements, different designers may make different design schemes. In order to obtain the optimal solution, the designers often need to design a series of schemes and to evaluate these schemes with some evaluation methods. The designers' experience and the owners' requirements and intentions play an important role in the process of designing, and these factors are often confusing. So it is the key for selecting the optimal ship form on how to deal with the relationship between fuzziness and quantitative analysis and between qualitative analysis and quantitative analysis. Fuzzy decision-making theory is used to study the quantitative relationship between ship form technical and economic parameters in the paper.

3.1. Comprehensive Evaluation Method. Fuzzy comprehensive evaluation (FCE) is based on fuzzy mathematics [12]. It applies fuzzy synthetic relationship principle to quantify some of the ill-defined or not easy to quantify factors. It is an important application of fuzzy mathematics in the field of natural science and social science [13-16]. According to the principle of fuzzy comprehensive evaluation, the multischeme optimization problem can be transformed into solving the evaluation vector $\mathbf{B}=\mathbf{A} \cdot \mathbf{R}$. So it is the key to determine the fuzzy evaluation indicator matrix $\mathbf{R}$ and the indicator importance vector $\mathbf{A}$ for the multischeme sorting and optimization [17-23].

3.2. Ship Form Fuzzy Comprehensive Evaluation Model. Fuzzy comprehensive evaluation method includes three parts. The first part is a set of alternative options, referred to as scheme set. The second one consists of evaluation factors or indicators, referred to as indicator set $U=\left\{u_{1}, u_{2}, \ldots, u_{n}\right\}$. The third one is single factor evaluation. On the basis of single factor evaluation, the ship form fuzzy comprehensive evaluation is carried out. The types of three elements are further determined as follows.

(1) Definition Scheme Set. The scheme set is composed of a series of design schemes $V=\left\{v_{1}, v_{2}, \ldots, v_{n}\right\}$.

(2) Determining the Evaluation Factor and Constructing Indicator Set. Select the factor that can reflect the quality of the ship form scheme as the indicator. These indicators are made up of the indicator set, denoted as $U=\left\{u_{1}, u_{2}, \ldots, u_{n}\right\}$.

(3) Evaluation of the Indicator Set. For each indicator in every ship form scheme, there is always a desired value $q_{i}$ and the allowable value $m_{i}$. For any fuzzy subset $A_{i}$, it is defined as the optimal value in its interval. The fuzzy subset $A_{i}$ is defined as

$$
A_{i}=\int \frac{\mu_{A_{i}}\left(u_{i}\right)}{u_{i}}
$$

where $\mu_{A_{i}}\left(u_{i}\right)$ is the satisfaction function of $u_{i}$; it is characterized by the degree of satisfaction of the corresponding evaluation indicator.

When the degree of satisfaction is monotonically increasing with the increase of the evaluation index, the form of $\mu_{A_{i}}\left(u_{i}\right)$ is

$$
\mu_{A_{i}}\left(u_{i}\right)= \begin{cases}0 & u_{i} \leq m_{i} \\ L_{i}\left(u_{i}\right) & m_{i}<u_{i}<q_{i} \\ 1 & u_{i} \geq q_{i} .\end{cases}
$$

When the degree of satisfaction is monotonically decreasing with the decrease of the evaluation index, the form of $\mu_{A_{i}}\left(u_{i}\right)$ is

$$
\mu_{A_{i}}\left(u_{i}\right)= \begin{cases}0 & u_{i} \leq q_{i} \\ L_{i}\left(u_{i}\right) & q_{i}<u_{i}<m_{i} \\ 1 & u_{i} \geq m_{i}\end{cases}
$$

The ship form comprehensive evaluation indicators can be obtained by evaluating their technical and economic performances for the scheme's every evaluation indicator. After obtaining the ship form scheme's comprehensive evaluation indicators, its fuzzy indicator can be obtained by drawing the curve of the degree of satisfaction. For each ship form 
scheme, each evaluation indicator is evaluated, and then the fuzzy evaluation indicator matrix can be obtained as follows:

$$
\mathbf{R}=\left[\begin{array}{cccc}
r_{11} & r_{12} & \cdots & r_{1 m} \\
r_{21} & r_{22} & \cdots & r_{2 m} \\
\vdots & \vdots & \ddots & \vdots \\
r_{n 1} & r_{n 2} & \cdots & r_{n m}
\end{array}\right]
$$

In the fuzzy matrix $\mathbf{R}$, each element of each row is expressed as the value of one evaluation indicator of the corresponding ship form scheme, which is corresponding to one unified set of evaluation criteria. Each element of each column is expressed as the value of every evaluation indicator of one certain ship form scheme. Thus, each fuzzy matrix is a single factor evaluation table.

3.3. Comprehensive Evaluation. According to the mentioned model, it is necessary to take into account many evaluation indicators and many complicated factors to obtain the optimal ship form scheme. Therefore, it is necessary to carry out comprehensive evaluation of the factors after the single factor evaluation. Because the importance of different factors (indicators) is different, they represent the different weight or degree.

There are $n$ factors of evaluation object $S$, and the evaluation value of each factor is $a_{i}(i=1,2, \ldots, n)$; then the total value of $S$ can be obtained as follows:

$$
S=\sum_{i=1}^{n} a_{i}
$$

Take $S$ as the evaluation criteria of the object $S$.

The weighted sum of the comprehensive evaluation method (or weighted average method) is also used. For the evaluation factor $a_{i}(i=1,2, \ldots, n)$ of the evaluation object $S$, if its weight $\lambda_{i}(i=1,2, \ldots, n)$ is given according to the importance of each factor, the weighted average evaluation value can be obtained:

$$
S=\sum_{i=1}^{n} \lambda_{i} a_{i}
$$

where $\lambda_{i} \geq 0$ and $\sum_{i=1}^{n} \lambda_{i}=1$.

Denote $\omega_{i}$ as the weight of the $i$ th factor, where $\omega_{i} \geq$ $0(i=1,2, \ldots, n)$. If $\omega=\sum_{i=1}^{n} \omega_{i}$ and $a_{i}=\omega_{i} / \omega$, then a fuzzy weight vector subset $\mathbf{A}=\left(a_{1}, a_{2}, \ldots, a_{n}\right)$ can be obtained by normalizing $\omega$, where $a_{i}$ is defined as the important degree of the $i$ th factor.

After determining the weight vector $\mathbf{A}$ and the single factor evaluation matrix $\mathbf{R}$, the fuzzy comprehensive evaluation problem can be solved as a fuzzy comprehensive evaluation vector $\mathbf{B}$ as follows:

$$
\begin{aligned}
\mathbf{B} & =\left(\begin{array}{llll}
a_{1} & a_{2} & \cdots & a_{n}
\end{array}\right)\left[\begin{array}{cccc}
r_{11} & r_{12} & \cdots & r_{1 m} \\
r_{21} & r_{22} & \cdots & r_{2 m} \\
\vdots & \vdots & \ddots & \vdots \\
r_{n 1} & r_{n 2} & \cdots & r_{n m}
\end{array}\right]=\mathbf{A} \cdot \mathbf{R} \\
& =\left(\begin{array}{llll}
b_{1} & b_{2} & \cdots & b_{m}
\end{array}\right),
\end{aligned}
$$

where $b_{j}=\bigvee_{i=1}^{n}\left(a_{i} \wedge r_{i j}\right),(j=1,2, \ldots, m)$; and symbol $\bigvee$ is taking small operation.

3.4. Ship Technical and Economic Parameters. The parameters of ship hull optimization are mainly composed of technical parameters and economic parameters.

3.4.1. Ship Form Technical Parameters. Ship form technical parameters mainly include ship displacement $\Delta$, ship form dimension as the length between perpendiculars $L_{\mathrm{pp}}$, width $B$, depth $D$, draft $d$, square coefficient $C_{b}$, lightweight LW, deadweight DW, cargo capacity $W_{c}$, main engine power BHP, the trial speed $V_{s}$, and rolling period $T_{\theta}$. The design variables and constraints would be determined before setting out calculation.

The design variables usually are taken as the length between perpendiculars $L_{\mathrm{pp}}$, width $B$, depth $D$, draft $d$, square coefficient $C_{b}$, and so forth.

3.4.2. Ship Form Operational and Economic Indicators. The purpose of operation and economic calculation is to predict the transport capacity of each ship form scheme in actual operation, namely, volume of freight turnover ATC. Therefore, it is necessary to calculate voyage freight volume, voyage time, and aerial number. The main content of the economic calculation is estimating the ship building cost $P$ of each ship form scheme and actual annual operation cost. Based on this, the further economic evaluation indicator of ship form scheme can be obtained, such as investment payback period (PBP) and net present value (NPV); accordingly, the optimal ship form scheme can be gotten.

\subsubsection{Main Ship Form Technical and Economic Parameters} Calculation. The paper only discusses the main economic indicators and the ship principal dimensions which have decisive influence on the mentioned economic indicators. The main parameters of ship form are ship length, width, depth, draft, displacement, deadweight, and block coefficient. The main economic indicators are ship manufacturing cost, investment payback period, net present value, and so forth. The main parameters are given by the following formula.

Block coefficient can be obtained by

$$
C_{B}=\frac{\Delta}{k \times \rho \times L_{\mathrm{pp}} \times B \times T},
$$


where $\Delta$ is ship displacement, $k$ is volume coefficient of the appendages, $\rho$ is water density, $L_{\mathrm{pp}}$ is ship length between perpendiculars, $B$ is ship width, and $T$ is ship draft.

Deadweight can be obtained by

$$
\mathrm{DW}=\mathrm{IDWRCW} \times \mathrm{CW} \text {, }
$$

where IDWRCW is the ratio of the deadweight to the cargo capacity; IDWRCW can be obtained with the mother ship.

Ship speed can be obtained with Admiralty coefficient method as follows:

$$
V=\sqrt[3]{\frac{C_{E} \times P_{E}}{\Delta^{2 / 3}}}
$$

where $C_{E}$ is Admiralty coefficient, $P_{E}$ is main engine power, and $\Delta$ is ship displacement.

Manufacturing cost can be obtained by

$$
P=0.0884 e^{0.0102 L_{\mathrm{pp}}} L_{\mathrm{pp}} \cdot B \cdot D,
$$

where manufacturing cost $P$ refers to the cost of ship manufacturing.

Annual cargo capacity can be obtained by

$$
\mathrm{ATC}=\mathrm{RIY} \times\left(\mathrm{DW}_{\text {down-flow }}+\mathrm{DW}_{\text {contra-flow }}\right),
$$

where RIY means annual round trip frequency, $\mathrm{DW}_{\text {down-flow }}$ is the cargo capacity downstream, and $\mathrm{DW}_{\text {contra-flow }}$ means the cargo capacity upstream.

Payback period can be obtained by

$$
\mathrm{PBP}=\frac{\log (A /(A-P \times i))}{\log (1+i)},
$$

where payback period PBP means the period of cost recovery and $A$ is annual income, $i$ is loaning rate, and $P$ is ship manufacturing cost.

Net present value can be obtained by

$$
\mathrm{NPV}=(B-Y)\left(\frac{P}{A}, i \%, n\right)+\Delta P\left(\frac{P}{F}, i \%, n\right)-P,
$$

where net present value (NPV) is the difference between the present value of the cash inflow of a project and the present value of the cash flow in the implementation of the plan. $B$ is annual earnings; $Y$ is annual operating expenses. $(P / A, i \%, n)$ is equal present value factor. $\Delta P$ is residual value of ship price, and $(P / F, i \%, n)$ is present value factor.

3.5. Calculation Processes and Flowchart. According to the principle of fuzzy comprehensive evaluation and ship form optimization, the procedures of ship form optimization are given as follows with fuzzy decision-making method:

(1) Ship form technical and economic parameters selected

(2) Ship form technical and economic indicators calculated

(3) Ship form scheme evaluation and sorting

(4) Determining the optimal ship form scheme

(5) Sensitivity analysis of indicator

The flowchart of technical and economical evaluation for ship form optimization is shown in Figure 1.

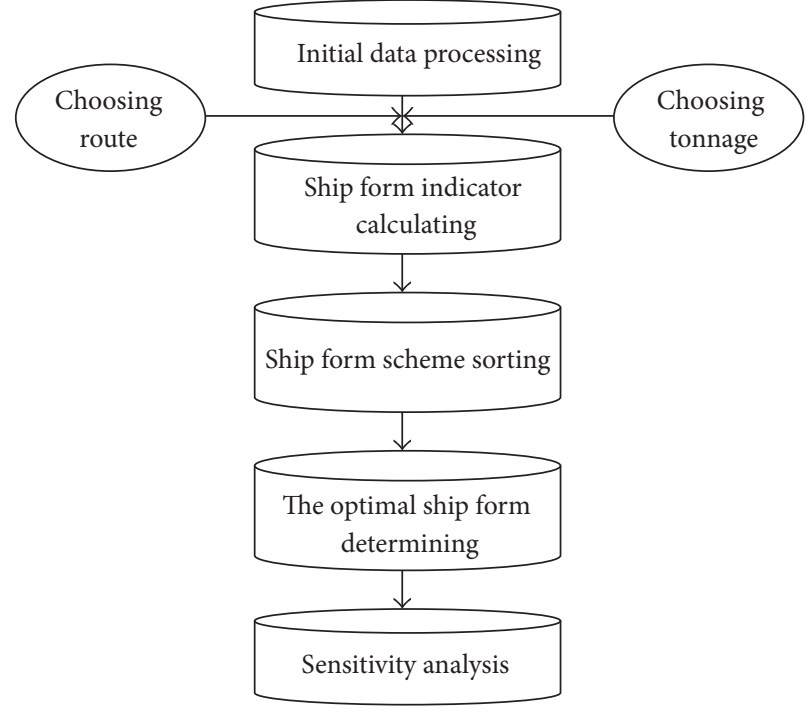

FIGURE 1: The flowchart of technical and economical evaluation for ship form optimization.

TABLE 1: The ship basic parameters.

\begin{tabular}{lccc}
\hline & $\begin{array}{c}\text { Length between } \\
\text { perpendiculars } \\
(\mathrm{m})\end{array}$ & $\begin{array}{c}\text { Molded breadth } \\
(\mathrm{m})\end{array}$ & $\begin{array}{c}\text { Designed draft } \\
(\mathrm{m})\end{array}$ \\
\hline Max. & 80 & 12.6 & 3.6 \\
Min. & 68 & 16.2 & 4.4 \\
\hline
\end{tabular}

TABLE 2: Main engine parameters.

\begin{tabular}{lccc}
\hline $\begin{array}{l}\text { Main engine } \\
\text { type }\end{array}$ & $\begin{array}{c}\text { Main power } \\
(\mathrm{kW})\end{array}$ & $\begin{array}{c}\text { Fuel consumption rate } \\
(\mathrm{g} / \mathrm{kW} \cdot \mathrm{h})\end{array}$ & $\begin{array}{c}M / E \text { speed } \\
(\mathrm{r} / \mathrm{min})\end{array}$ \\
\hline WD618.C-3 & 210 & 198 & 2150 \\
WD618.C-2 & 240 & 198 & 2150 \\
WD618.C-1 & 275 & 198 & 2150 \\
\hline
\end{tabular}

\section{Examples Demonstration}

In order to verify the applicability and correctness of the presented method, the paper selects 3000 tons of dry bulk cargo ship sailing in the Pearl River main line as an example study. According to the actual situation of the main channel of the Pearl River, we choose the ship basic parameters as shown in Table 1 as the basic parameters.

The main engine types are chosen as shown in Table 2 for the 3000-ton cargo ship in the Pearl River main line.

4.1. Hull Form Parameter. The example selects the length between perpendiculars $L_{\mathrm{pp}}$, width $B$, depth $D$, draft $d$, and main engine power BHP as the basic ship form parameters. The basic technical indicators are taken as the square coefficient $C_{b}$, deadweight DW, and the ship speed $V$. The basic economic indicators are taken as volume of freight turnover ATC, ship building cost $P$, investment payback period (PBP), net present value (NPV), and so forth. The ship's economic 
TABLE 3: Scheme of variable value method.

\begin{tabular}{|c|c|c|c|c|c|}
\hline Number & $\begin{array}{l}L_{\mathrm{pp}} \\
(\mathrm{m})\end{array}$ & $\begin{array}{c}B \\
(\mathrm{~m}) \\
\end{array}$ & $\begin{array}{c}T \\
(\mathrm{~m})\end{array}$ & $\begin{array}{c}D \\
(\mathrm{~m})\end{array}$ & $\begin{array}{c}P_{E} \\
(\mathrm{~kW})\end{array}$ \\
\hline 1 & 68.00 & 12.60 & 3.60 & 4.250 & 210 \\
\hline 2 & 68.00 & 12.60 & 3.80 & 4.450 & 210 \\
\hline 3 & 68.00 & 12.60 & 4.00 & 4.657 & 210 \\
\hline 4 & 68.00 & 12.60 & 4.20 & 4.869 & 210 \\
\hline 5 & 68.00 & 12.60 & 4.40 & 5.081 & 210 \\
\hline 6 & 68.00 & 12.60 & 3.60 & 4.250 & 240 \\
\hline 7 & 68.00 & 12.60 & 3.80 & 4.450 & 240 \\
\hline 8 & 68.00 & 12.60 & 4.00 & 4.657 & 240 \\
\hline 9 & 68.00 & 12.60 & 4.20 & 4.869 & 240 \\
\hline 10 & 68.00 & 12.60 & 4.40 & 5.081 & 240 \\
\hline 11 & 68.00 & 12.60 & 3.60 & 4.250 & 275 \\
\hline 12 & 68.00 & 12.60 & 3.80 & 4.450 & 275 \\
\hline 13 & 68.00 & 12.60 & 4.00 & 4.657 & 275 \\
\hline 14 & 68.00 & 12.60 & 4.20 & 4.869 & 275 \\
\hline 15 & 68.00 & 12.60 & 4.40 & 5.081 & 275 \\
\hline
\end{tabular}

TABLE 4: Calculation results of technical and economic parameters.

\begin{tabular}{|c|c|c|c|c|c|c|c|}
\hline Number & $C_{B}$ & $\begin{array}{c}\text { DW } \\
(\mathrm{t})\end{array}$ & $\begin{array}{c}V \\
(\mathrm{~km} / \mathrm{h}) \\
\end{array}$ & $\begin{array}{c}P \\
\text { (million Yuan) }\end{array}$ & $\begin{array}{c}\text { ATC } \\
(\mathrm{t})\end{array}$ & $\begin{array}{c}\mathrm{PBP} \\
\text { (year) }\end{array}$ & $\begin{array}{c}\text { NPV } \\
\text { (million Yuan) }\end{array}$ \\
\hline 1 & 0.843 & 2614 & 16.5 & 966.00 & 266200 & 2.93 & 0.100 \\
\hline 2 & 0.807 & 2642 & 16.5 & 1012.00 & 265936 & 3.16 & 0.095 \\
\hline 3 & 0.774 & 2670 & 16.4 & 1059.00 & 262570 & 3.52 & 0.088 \\
\hline 4 & 0.746 & 2699 & 16.4 & 1107.00 & 255904 & 4.07 & 0.078 \\
\hline 5 & 0.719 & 2728 & 16.4 & 1155.00 & 248930 & 4.77 & 0.066 \\
\hline 6 & 0.843 & 2614 & 17.3 & 966.00 & 271260 & 2.96 & 0.097 \\
\hline 7 & 0.807 & 2642 & 17.2 & 1012.00 & 270996 & 3.20 & 0.092 \\
\hline 8 & 0.774 & 2670 & 17.2 & 1059.00 & 267608 & 3.56 & 0.085 \\
\hline 9 & 0.746 & 2699 & 17.1 & 1107.00 & 260876 & 4.13 & 0.074 \\
\hline 10 & 0.719 & 2728 & 17.1 & 1155.00 & 253847 & 4.86 & 0.063 \\
\hline 11 & 0.843 & 2614 & 18.1 & 966.00 & 276309 & 3.02 & 0.093 \\
\hline 12 & 0.807 & 2642 & 18.0 & 1012.00 & 276067 & 3.25 & 0.089 \\
\hline 13 & 0.774 & 2670 & 18.0 & 1059.00 & 272657 & 3.63 & 0.081 \\
\hline 14 & 0.746 & 2699 & 17.9 & 1107.00 & 265881 & 4.23 & 0.071 \\
\hline 15 & 0.719 & 2728 & 17.9 & 1155.00 & 258797 & 5.00 & 0.059 \\
\hline
\end{tabular}

evaluation indicator can be obtained according to these parameters.

4.2. Constructing Ship Form Schemes. In the paper, the variable value method is employed to construct a series of ship form schemes. Variable value method is also known as grid method. Its basic principle is to construct a series of design variables in the scope of the ship's form dimension, which is allowed to change in the scope of the ship's main dimensions, according to the requirements of the ship's operation and the restriction of the ship's main dimensions. Then, by employing combination method, a serial of ship schemes are generated, and the technical and economic indicators of each scheme are calculated. On this basis, the evaluation indicators of the ship schemes are obtained. Finally, the optimal ship form is preferred. As the combination schemes are more, the paper only lists the top 15 schemes as shown in Table 3, as the combination schemes are much more than what we have shown in Table 3.

4.3. Ship Technical and Economic Parameters Calculation. According to the ship form parameters constructed, the corresponding ship form technical and economic parameters can be obtained, as shown in Table 4 .

4.4. Ship Form Decision-Making Evaluation Indicator. According to the fuzzy decision-making model, the ship form evaluation indicators can be obtained as shown in Table 5 . 
TABLE 5: Calculation results of ship form evaluation index.

\begin{tabular}{|c|c|c|c|c|c|c|c|c|c|c|c|}
\hline Number & $\begin{array}{l}L_{\mathrm{pp}} \\
(\mathrm{m})\end{array}$ & $\begin{array}{c}B \\
(\mathrm{~m}) \\
\end{array}$ & $\begin{array}{c}T \\
(\mathrm{~m}) \\
\end{array}$ & $\begin{array}{c}D \\
(\mathrm{~m}) \\
\end{array}$ & $\begin{array}{c}P_{E} \\
(\mathrm{~kW})\end{array}$ & $\begin{array}{c}\text { DW } \\
(\mathrm{t})\end{array}$ & $\begin{array}{c}P \\
\text { (million Yuan) }\end{array}$ & $\begin{array}{c}\text { ATC } \\
(\mathrm{t})\end{array}$ & $\begin{array}{c}\mathrm{PBP} \\
\text { (year) }\end{array}$ & $\begin{array}{c}\text { NPV } \\
\text { (million Yuan) }\end{array}$ & Sort index \\
\hline 1 & 68.00 & 12.60 & 3.60 & 4.250 & 210 & 2614 & 966 & 266200 & 2.93 & 0.100 & 0.529 \\
\hline 2 & 68.00 & 12.60 & 3.60 & 4.250 & 240 & 2614 & 966 & 271260 & 2.96 & 0.097 & 0.517 \\
\hline 3 & 68.00 & 12.60 & 3.80 & 4.450 & 210 & 2642 & 1012 & 265936 & 3.16 & 0.095 & 0.505 \\
\hline 4 & 68.00 & 12.60 & 3.60 & 4.250 & 275 & 2614 & 966 & 276309 & 3.02 & 0.093 & 0.495 \\
\hline 5 & 68.00 & 12.60 & 3.80 & 4.450 & 240 & 2642 & 1012 & 270996 & 3.20 & 0.092 & 0.489 \\
\hline 6 & 68.00 & 12.60 & 3.80 & 4.450 & 275 & 2642 & 1012 & 276067 & 3.25 & 0.089 & 0.483 \\
\hline 7 & 68.00 & 12.60 & 4.00 & 4.657 & 210 & 2670 & 1059 & 262570 & 3.52 & 0.088 & 0.477 \\
\hline 8 & 68.00 & 12.60 & 4.00 & 4.657 & 240 & 2670 & 1059 & 267608 & 3.56 & 0.085 & 0.461 \\
\hline 9 & 68.00 & 12.60 & 4.00 & 4.657 & 275 & 2670 & 1059 & 272657 & 3.63 & 0.081 & 0.437 \\
\hline 10 & 68.00 & 12.60 & 4.20 & 4.869 & 210 & 2699 & 1107 & 255904 & 4.07 & 0.078 & 0.423 \\
\hline 11 & 68.00 & 12.60 & 4.20 & 4.869 & 240 & 2699 & 1107 & 260876 & 4.13 & 0.074 & 0.401 \\
\hline 12 & 68.00 & 12.60 & 4.20 & 4.869 & 275 & 2699 & 1107 & 265881 & 4.23 & 0.071 & 0.381 \\
\hline 13 & 68.00 & 12.60 & 4.40 & 5.081 & 210 & 2728 & 1155 & 248930 & 4.77 & 0.066 & 0.357 \\
\hline 14 & 68.00 & 12.60 & 4.40 & 5.081 & 240 & 2728 & 1155 & 253847 & 4.86 & 0.063 & 0.339 \\
\hline 15 & 68.00 & 12.60 & 4.40 & 5.081 & 275 & 2728 & 1155 & 258797 & 5.00 & 0.059 & 0.321 \\
\hline
\end{tabular}

TABLE 6: Final results of ship form optimization.

\begin{tabular}{lcccc}
\hline $\begin{array}{l}L_{\mathrm{pp}} \\
(\mathrm{m})\end{array}$ & $B$ & $T$ & $D$ & $P_{E}$ \\
$(\mathrm{~kW})$
\end{tabular}

4.5. Results Analysis. According to the calculation results, the optimal ship form scheme can be obtained as shown in Table 6.

In order to further verify the correctness of the method, this paper uses the analytic hierarchy process (AHP) in the optimization sort analysis to calculate and compare the results. The results employing AHP are shown in Table 7.

The conclusions can be gotten from Tables 7 and 5, in which the weight sort is consistent with the sort index by the paper presented method.

Actually, the optimization result is consistent with the main dimension parameters of the 3000-tonnage dry bulk cargo ship which is running on the main line of the Pearl River. It verifies that the method proposed in the paper is available.

4.6. Results Analysis. Further, we research the relationship between ship form parameters and economic indicators. According to Tables 4 and 5, the relationship figure of the net present value (NPV) and deadweight can be drawn as Figure 2. In Figure 2, the horizontal coordinate is ship deadweight, and the longitudinal axis is the net present value (NPV).

Conclusions can be drawn on the relationship between the net present value (NPV) and deadweight (DW) from Figure 2. Firstly, ship form principal dimension determines its deadweight tonnage. Secondly, under the same DWT, the main engine power determines the net present value (NPV); if the main engine power is greater, the speed $V$ is greater, but

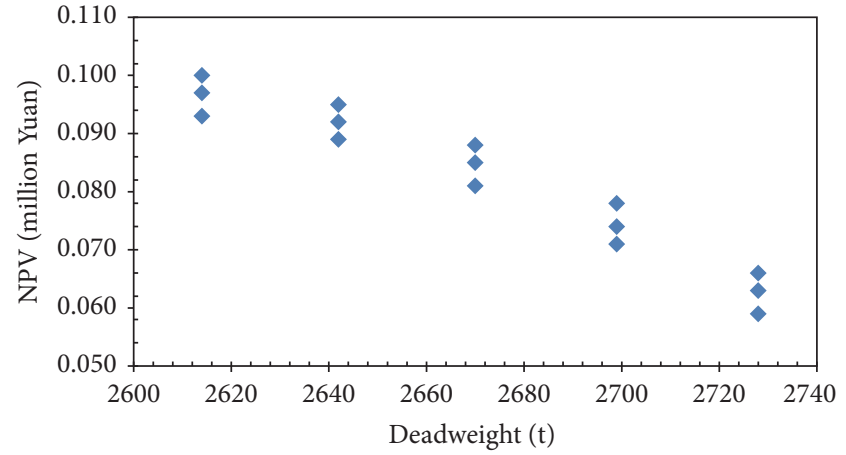

Figure 2: The distribution of NPV.

the NPV is lower. Thirdly, with the increase of the deadweight, the NPV is becoming smaller and smaller.

According to Table 5, there is the relationship figure between the payback period and the deadweight as shown in Figure 3. In Figure 3, the horizontal coordinate is ship deadweight, and the longitudinal axis is the payback period (PBP).

Conclusions can be drawn on the relationship between the payback period (PBP) and deadweight from Figure 3. Firstly, under the same DWT, if the main engine power is greater, payback period of investment is longer. Secondly, with the increase of the deadweight and the main engine power, $\mathrm{PBP}$ is becoming larger and larger. 
TABLE 7: Calculation weight results of ship evaluation index.

\begin{tabular}{|c|c|c|c|c|c|c|c|}
\hline Number & $\begin{array}{l}L_{\mathrm{pp}} \\
(\mathrm{m})\end{array}$ & $\begin{array}{c}B \\
(\mathrm{~m})\end{array}$ & $\begin{array}{c}T \\
(\mathrm{~m})\end{array}$ & $\begin{array}{c}D \\
(\mathrm{~m})\end{array}$ & $\begin{array}{c}P_{E} \\
(\mathrm{~kW})\end{array}$ & $\begin{array}{c}\text { DW } \\
(\mathrm{t})\end{array}$ & Wight sort \\
\hline 1 & 68 & 12.60 & 3.60 & 4.25 & 210 & 2614 & 0.0800 \\
\hline 2 & 68 & 12.60 & 3.60 & 4.25 & 240 & 2614 & 0.0782 \\
\hline 3 & 68 & 12.60 & 3.80 & 4.45 & 210 & 2642 & 0.0763 \\
\hline 4 & 68 & 12.60 & 3.60 & 4.25 & 275 & 2614 & 0.0748 \\
\hline 5 & 68 & 12.60 & 3.80 & 4.45 & 240 & 2642 & 0.0739 \\
\hline 6 & 68 & 12.60 & 3.80 & 4.45 & 275 & 2642 & 0.0730 \\
\hline 7 & 68 & 12.60 & 4.00 & 4.66 & 210 & 2670 & 0.0721 \\
\hline 8 & 68 & 12.60 & 4.00 & 4.66 & 240 & 2670 & 0.0697 \\
\hline 9 & 68 & 12.60 & 4.00 & 4.66 & 275 & 2670 & 0.0661 \\
\hline 10 & 68 & 12.60 & 4.20 & 4.87 & 210 & 2699 & 0.0639 \\
\hline 11 & 68 & 12.60 & 4.20 & 4.87 & 240 & 2699 & 0.0606 \\
\hline 12 & 68 & 12.60 & 4.20 & 4.87 & 275 & 2699 & 0.0576 \\
\hline 13 & 68 & 12.60 & 4.40 & 5.08 & 210 & 2728 & 0.0540 \\
\hline 14 & 68 & 12.60 & 4.40 & 5.08 & 240 & 2728 & 0.0512 \\
\hline 15 & 68 & 12.60 & 4.40 & 5.08 & 275 & 2728 & 0.0485 \\
\hline
\end{tabular}

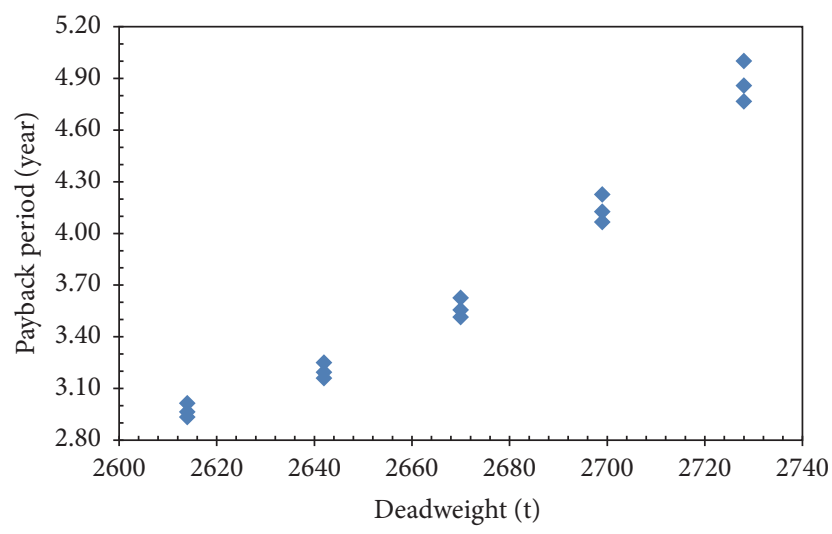

FIgURE 3: The distribution of PBP.

According to Table 5, we can obtain Figure 4 which describes the relationship between the ship form dimension and fuzzy evaluation indicators. In Figure 4, the horizontal coordinate is ship deadweight, and the longitudinal axis is the sort index.

Conclusions can be drawn on the relationship between the fuzzy evaluation indicator and ship deadweight from Figure 4. Firstly, under the same DWT, if the main engine power is greater, evaluation index is smaller. Secondly, there is an optimization evaluation value in a certain interval, where this value is corresponding to the optimal ship form scheme (including the main engine power).

\section{Sensitivity Analysis}

In order to further analyze the influence of each indicator on the ship form scheme selected, it is necessary to analyze its sensitivity. There is the influence factor of ship form parameters such as fuel price, ship price, and freight. In the

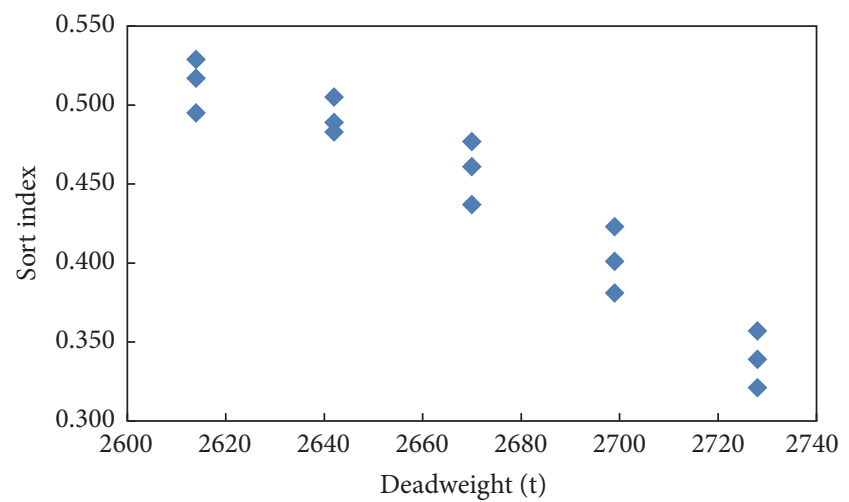

Figure 4: Evaluation indicator change chart with deadweight.

paper, there are selected fuel price, ship price, and freight as sensitive parameters to analyze their influence on the ship technical and economic indicator performance (PBP and NPV). The variation range of the parameters is taken as $25 \%$, $20 \%, 15 \%, 10 \%$, and $5 \%$. There is the rate of PBP changing as shown in Table 8.

According to Table 8, the curve of the PBP changing can be obtained as shown in Figure 5.

Conclusions can be drawn from the sensitivity curve of PBP as shown in Figure 5. Firstly, the investment payback period (PBP) is decreased with the increase of fuel price and ship price, and the increase of freight makes PBP longer. Secondly, the impact of freight on the payback period PBP is the strongest.

There is the rate of NPV changing as shown in Table 9.

According to Table 9, the curve of the NPV changing can be obtained as shown in Figure 6.

Conclusions can be drawn from the sensitivity curve of NPV as follows. Firstly, the net present value (NPV) is 
TABLE 8: The sensibility result of PBP.

\begin{tabular}{lcccccccccccc}
\hline Change rate (\%) & -25 & -20 & -15 & -10 & -5 & 0 & 5 & 10 & 15 & 20 & 25 \\
\hline Fuel price & 1.11 & 1.09 & 1.07 & 1.05 & 1.02 & 1.00 & 0.98 & 0.95 & 0.93 & 0.91 & 0.89 \\
Ship price & 1.25 & 1.20 & 1.15 & 1.10 & 1.05 & 1.00 & 0.95 & 0.90 & 0.85 & 0.80 & 0.75 \\
Freight & 0.35 & 0.48 & 0.61 & 0.74 & 0.87 & 1.00 & 1.13 & 1.26 & 1.39 & 1.52 & 1.65 \\
\hline
\end{tabular}

TABLE 9: The sensibility result of NPV.

\begin{tabular}{lcccccccccccc}
\hline Change rate (\%) & -25 & -20 & -15 & -10 & -5 & 0 & 5 & 10 & 15 & 20 \\
\hline Fuel price & 0.92 & 0.93 & 0.95 & 0.97 & 0.98 & 1.00 & 1.02 & 1.04 & 1.06 & 1.08 & 1.10 \\
Ship price & 0.66 & 0.72 & 0.78 & 0.85 & 0.92 & 1.00 & 1.08 & 1.17 & 1.26 & 1.35 & 1.46 \\
Freight & 2.05 & 1.69 & 1.44 & 1.26 & 1.11 & 1.00 & 0.91 & 0.83 & 0.77 & 0.71 & 0.66 \\
\hline
\end{tabular}

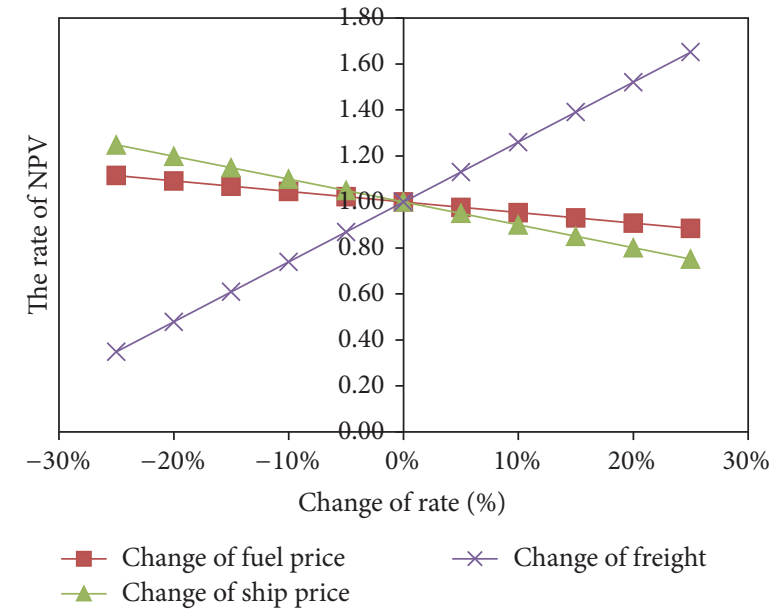

FIGURE 5: The sensibility analysis curve of PBP.

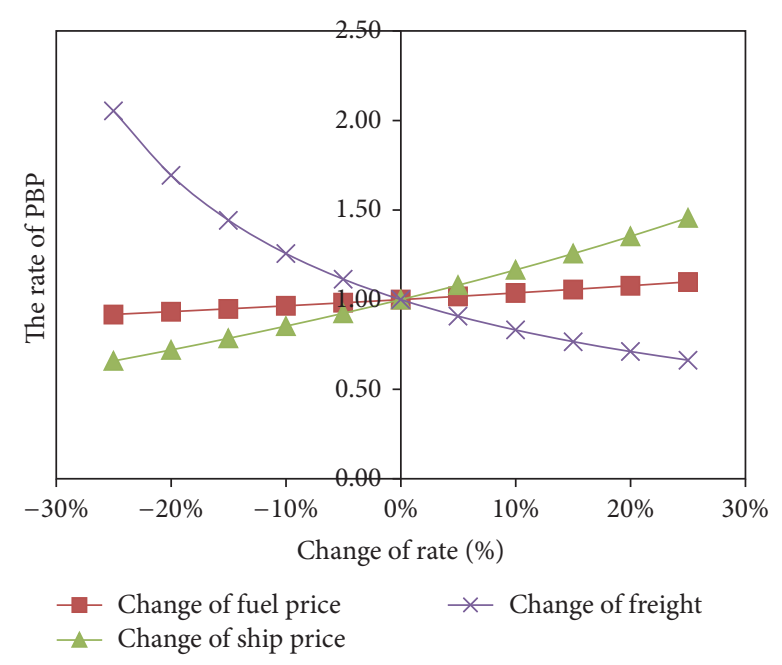

FIgURE 6: The sensibility analysis curve of NPV.

increased with the increase of fuel price and ship price, and the increase of freight makes NPV decrease. Secondly, the impact of freight on the net present value NPV is the most strong.

\section{Conclusions}

Based on the fuzzy decision-making theory, the paper presented a method for evaluating the economic performance of ship form optimization. By the example demonstration of 3000-ton bulk cargo ship in the Pearl River main line, the main conclusions are drawn: ship form principal dimensions (DW) directly affect the ship main economic indicators such as the payback period and the net present value. The results of the case study are in agreement with the practice, which verifies the correctness and efficiency of the proposed method. The economic evaluation method proposed is theoretical and practical value for ship form scheme optimization with fuzzy decision-making model in the paper. The paper only applied one kind of fuzzy decision-making model; in the future research, we can employ a variety of fuzzy decision models to compare and make the second fuzzy decisionmaking analysis.

\section{Competing Interests}

The authors declare that they have no competing interests.

\section{Acknowledgments}

This work is partially supported by Guangdong Traffic Science and Technology (Project no. 2015-02-050) and Guangdong Natural Science Foundation (Project no. 2014A030313792 and no. 2016A030313125). It is also supported by China Postdoctoral Science Foundation (Project no. 2015M581622).

\section{References}

[1] L. Yang, X. Li, M. Ding, and L. Huang, "Application of multiobjective genetic algorithm and decision-making skills in ship form evaluation," Journal of Harbin Engineering University, vol. 33, no. 12, pp. 1459-1464, 2012.

[2] Y. J. Chen, "Application of fast non-dominated sorted genetic algorithm and principle component analysis in ship main dimensions design," Ship \& Ocean Engineering, vol. 44, no. 2, pp. 31-35, 2015.

[3] L. P. Ding and X. H. Zhang, "Application of required rate in analysis of economiccal ship style and comparison of options," Port Engineering Technology, vol. 51, no. 4, pp. 63-65, 2014. 
[4] T. C. Koopmans, "Analysis of production as an efficient combination of activities," in Activity Analysis of Production and Allocation, T. C. Koopmans, Ed., pp. 33-97, John Wiley \& Sons, New York, NY, USA, 1951.

[5] M. L. Rasulov, "An effective solution of mixed problems for parabolic equations," Doklady Akademii Nauk SSSR, vol. 128, pp. 478-481, 1959.

[6] W. L. Li and J. H. Tan, "Optimization of container ship principal parameters based on minimum- deviation method," Shipbuilding of China, vol. 43, no. 4, pp. 1-5, 2002.

[7] M. M. Guin, H. Kato, H. Yamaguchi, M. Maeda, and M. Miyanaga, "Reduction of skin friction by microbubbles and its relation with near-wall bubble concentration in a channel," Journal of Marine Science and Technology, vol. 1, no. 5, pp. 241254, 1996.

[8] E. Besnard, A. Schmitz, H. Hefazi, and R. Shinde, "Constructive neural networks and their application to ship multi-disciplinary design optimization," Journal of Ship Research, vol. 51, no. 4, pp. 297-312, 2007.

[9] Y. T. Chen, G. L. Chen, and M. J. Li, "Classification \& research advancement of comprehensive evaluation methods," Journal of Management Sciences in China, no. 2, pp. 69-79, 2004.

[10] H. Kim, S. Jeong, C. Yang, and F. Noblesse, "Hull form design exploration based on response surface method," in Proceedings of the 21st International Offshore and Polar Engineering Conference (ISOPE '11), pp. 816-825, Maui, Hawaii, USA, June 2011.

[11] Y. D. Liu, X. L. Yu, and S. J. Su, "Techinical and economic evaluation for the container ships in Xijiang river," Ship \& Ocean Engineering, vol. 40, no. 2, pp. 9-13, 2011.

[12] C. Carlsson and R. Fullér, "Fuzzy multiple criteria decision making: recent developments," Fuzzy Sets and Systems, vol. 78, no. 2, pp. 139-153, 1996.

[13] J.-Q. Wang and J.-J. Li, "Multi-criteria fuzzy decision-making method based on cross entropy and score functions," Expert Systems with Applications, vol. 38, no. 1, pp. 1032-1038, 2011.

[14] H. Liao and Z. Xu, "A VIKOR-based method for hesitant fuzzy multi-criteria decision making," Fuzzy Optimization and Decision Making, vol. 12, no. 4, pp. 373-392, 2013.

[15] H. Liao and Z. Xu, "Satisfaction degree based interactive decision making under hesitant fuzzy environment with incomplete weights," International Journal of Uncertainty, Fuzziness and Knowledge-Based Systems, vol. 22, no. 4, pp. 553-572, 2014.

[16] J.-Q. Wang, R.-R. Nie, H.-Y. Zhang, and X.-H. Chen, "Intuitionistic fuzzy multi-criteria decision-making method based on evidential reasoning," Applied Soft Computing, vol. 13, no. 4, pp. 1823-1831, 2013.

[17] J. Ramik and M. Vlach, "Fuzzy mathematical programming: a unified approach based on fuzzy relations," Fuzzy Optimization \& Decision Making, vol. 1, no. 4, pp. 335-346, 2002.

[18] F. Jiménez, G. Sánchez, and P. Vasant, "A multi-objective evolutionary approach for fuzzy optimization in production planning," Journal of Intelligent and Fuzzy Systems, vol. 25, no. 2, pp. 441-455, 2013.

[19] A. Memari, A. R. A. Rahim, and R. B. Ahmad, "An integrated production-distribution planning in green supply chain: a multi-objective evolutionary approach," Procedia Cirp, vol. 26, pp. 700-705, 2015.

[20] B. Bairagi, B. Dey, B. Sarkar, and S. K. Sanyal, "A De Novo multiapproaches multi-criteria decision making technique with an application in performance evaluation of material handling device," Computers \& Industrial Engineering, vol. 87, pp. 267282, 2015.
[21] A. Kelemenis and D. Askounis, "A new TOPSIS-based multicriteria approach to personnel selection," Expert Systems with Applications, vol. 37, no. 7, pp. 4999-5008, 2010.

[22] I. B. Turksen, "Interval valued fuzzy sets based on normal forms," Fuzzy Sets and Systems, vol. 20, no. 2, pp. 191-210, 1986.

[23] V. Torra, "Hesitant fuzzy sets," International Journal of Intelligent Systems, vol. 25, no. 6, pp. 529-539, 2010. 


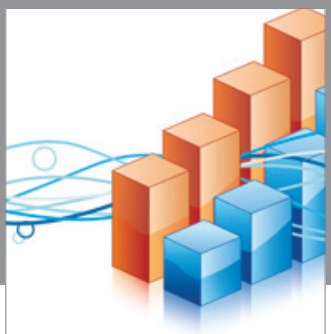

Advances in

Operations Research

vatem alat4

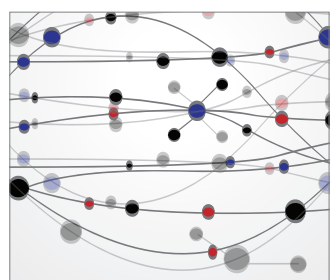

\section{The Scientific} World Journal
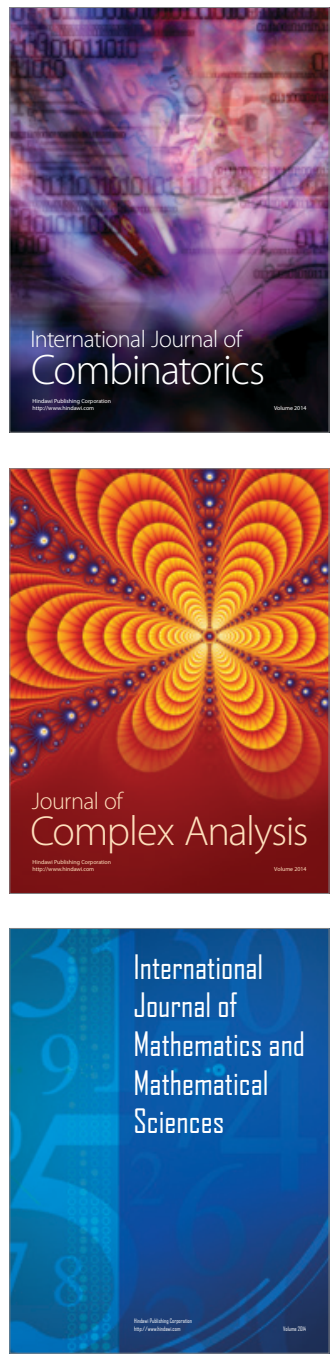
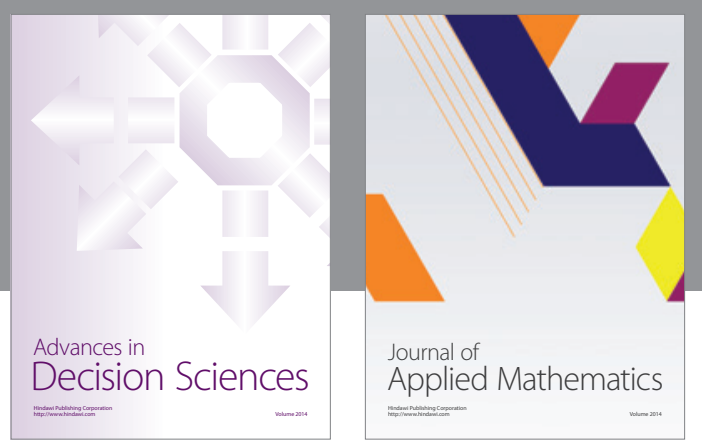

Algebra

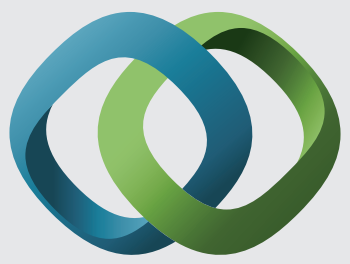

\section{Hindawi}

Submit your manuscripts at

http://www.hindawi.com
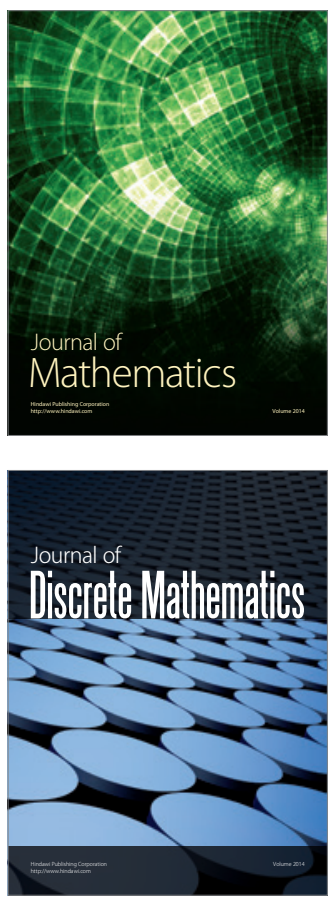

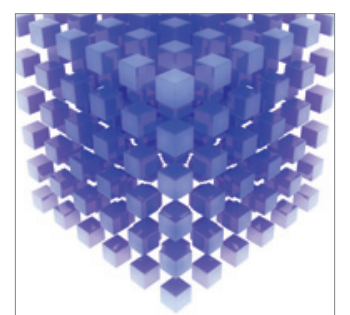

Mathematical Problems in Engineering
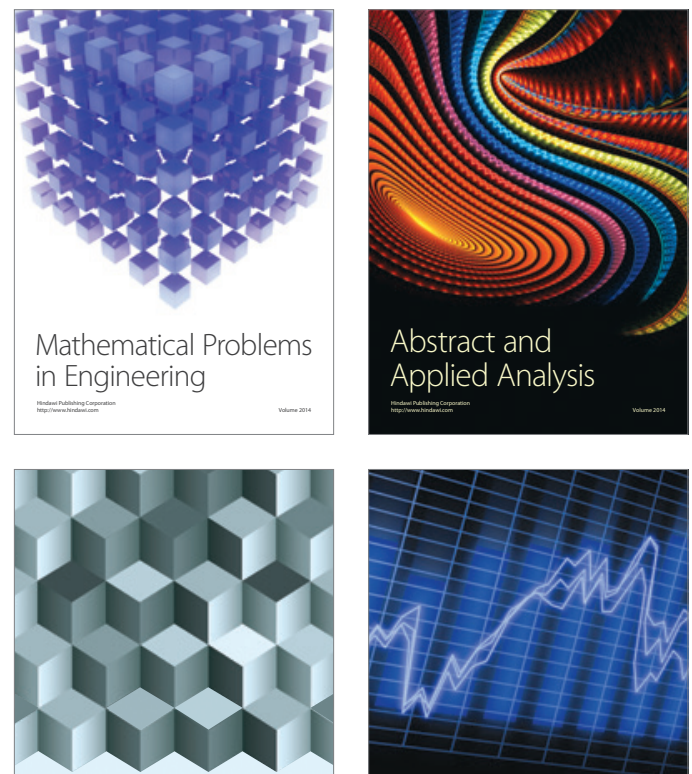

Journal of

Function Spaces

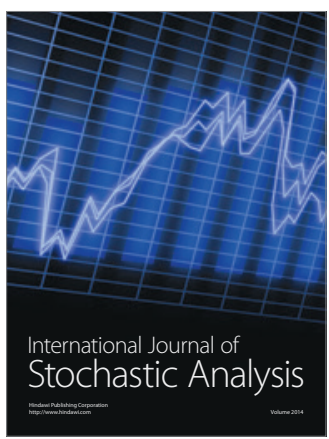

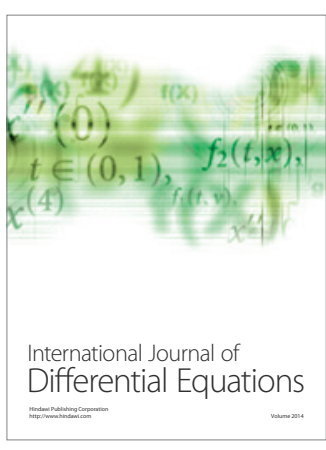
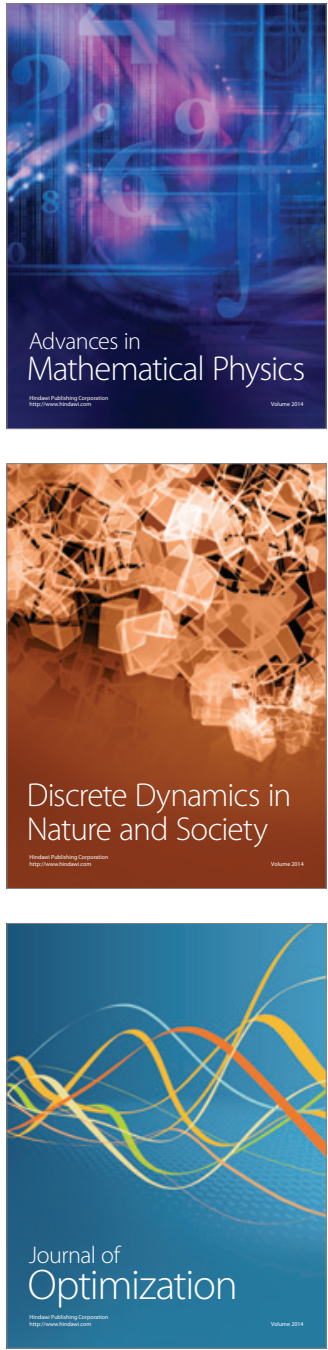